\title{
The research potential of a computer-based cathode-ray tube display system ${ }^{1}$
}

\section{S. MAYZNER, NEW YORK UNIVERSITY, NEW York, N.Y.}

The objectives of the present paper are (1) to outline briefly the very great research potential of a computer-based cathode-ray tube (CRT) display system for studies in visual perception. learning, and memory, (2) to discuss the hardware and software components of such systems with reference to a particular system currently in use, and (3) to describe some of the advantages and disadvantages of such systems for conducting behavioral research.

In the most general sense, problems of visual perception, leaming, and memory all involve the presentation to $S$ of some input or sequence of inputs, arrayed in space and time, that requires some type of output or $S$ response. Over the past several decades experimental psychologists have demonstrated their ingenuitv in constructing a vast variety' of devices to accomplish this objective; Sidowski's (1966) excellent book attests to the diverse instrumentation that presently characterizes our field. It is clear, from a careful reading of this book, that the general instrumentation problem that cuts again and again across the fields of visual perception, learning, and memory is one of both spatially and temporally controlling the input array and of recording and timing $S$ 's output or response. To this end, experimental psychologists have constructed such devices as tachistoscopes, memory druns, elaborate projection systems, etc. It is certainly not the purpose of this paper to review these efforts. Rather, we hope to demonstrate that a computer-based CRT display facility can often proride in a single instrumentation complex all of the advantages of the several separate packages that currently are found in present day experimental psychology laboratories, and more importantly add a flexibility of input and output control that has never before been possible.

For example. a computer-based CRT display system can provide one. for all practical purposes, with an $\mathrm{N}$-field tachistoscope (tach). where $\mathrm{N}$ could vary from one to 100 or even 1000 , if desired. The mmense advantages of such an $\mathrm{N}$-field tach for studies in visual perception are sufficiently obvious as to require no further elaboration. For studies in learning and memory, a central computer can drive or control simultaneously large numbers of CRTs, each with the same or different stimulus arrays being displayed. Further, with the appropriate $S$ input devices, such as teletype (TT) consoles. interfaced with the computer. and with the appropriate programming, all of the $S$ 's responses to the displayed information can be recorded by the computer while the experiment is in progress. Real-time analyses may be made of these responses and. if desired. can be employed to alter future stimulus presentations while the experiment is still in progress. Thus. such display systems make possible a whole spectrum of real-time feed-back loop studies of human behavior. never possible heretofore. Such computer-based CRT display systems have already been employed in a varicty of research contexts in a few laboratories. e.g.. Atkinson \& Shiffrin (1967). Kahneman (1967). Mayzner. Tresselt, \& Cohen (1966), Mayzner. Tresselt. \& Helfer (1967a; 1967b), and U/tal \& Smith (1968). Many other laboratories are currently developing such systems.

\section{HARDWARE AND SOFTWARE COMPONENTS OF A COMPUTER-BASED CRT DISPLAY SYSTEM}

\section{A. Hardware}

In selecting the hardware for a computer-based CRT display system, one is confronted with a large number of options, a situation which, with the rapidly expanding technology of this field, can only become further magnified in the foreseeable future. There is already a very wide choice of digital computers to choose from, a rather smaller choice with respect to CRTs. In order to focus on the hardware components in a specific manner. we shall briefly describe the system currently used in our laboratory. A more detailed description of a slightly earlier version of our system may be found in Mayzner. Tresselt, \& Helfer (1967a).

Our present system consists of a Digital Equipment Corp. PDP-7 digital computer with 8K, 18 bit words of core memory and 21 million bits of external tape storage. Coupled to and driven by the computer are four CRT display consoles. Two consoles are manufactured by the Digital Equipment Corp. and are their 340 Master Display and their 343 Slave Display. In addition, two Type 737A display consoles. manufactured by the Fairchild Camera and Instrument Corp., are also slaved to the 340 Master Display. The 340 Master Display is equipped with a 64 alpha-numeric character set generator (Type 342) and a subroutine interface (Type 347), which permits data display from arbitrarily located and nonconsecutive display tables within the PDP-7 memory. Both of these options are highly desirable in order to avoid excessive programming when employing the display consoles. The character set generator, for example. permits one to specify with a single 18 bit word three alpha-numeric characters for display, characters which otherwise would have to be plotted point by point requiring far more display time and far more programming.

Of critical importance in any computer-based CRT display system is the accuracy of the input display timing obtained, which is a function both of the decay characteristics of the phosphor used in coating the CRT display surface, and the timing system employed. With our current system a $20,000 \mathrm{~Hz}$ crystal clock is employed by the PDP-7 computer to provide timing pulses. This allows us to display inputs for as short a period as $50 \mu \mathrm{sec}$ and upward, in $50 \mu \mathrm{sec}$ increments. This statement needs to be cualified. however, since any given input being displayed is composed of a number of discrete points. Since each point requires $2 \mu \mathrm{sec}$ for intensification and positioning to the next point. the lower limit of $50 \mu \mathrm{sec}$ is possible only with an input array containing no more than 25 discrete points.

Phosphor decay time is the other major determinant of timing accuracy. Obviously, with a long decaying phosphor. little timing accuracy is possible. since the input will continue to be quite perceptible after the electron beam has stopped painting the input characters. This is due principally to phosphorescence, i.e., the light emission of the phosphor after the beam excitation has been stopped. Since the 340 Master Display is coated with a P7 phosphor whose persistence is very long (on the order of several seconds). the two Fairchild slave displays and the 343 slave 
display are coated with a P 24 phosphor, P 24 decay time is on the order of a few microseconds, which allows for extremely accurate timing of input arrays.

An additional parameter of some interest on any CRT display is the intensity of the emitted light from the display surface. With the 340 and 343 displays, eight different intensity levels are available under computer program control; we are currently planning to extend this capability to the two Fairchild displays In addition, we plan. with certain hardware modifications, to be able to vary each of these eight intensity levels in a continuous manner. This capability has considerable value. It enables one to manipulate intensity levels at different locations on the display surface independently of one another. This is highly desirable for certain types of studies in visual perception, where intensity is a parameter one wishes to vary independently of other display parameters, such as, input timing, input display order, input size, etc. In fact, as input size decreases on these CRTs, input intensity per unit area increases as a result of the individual display points being packed closer and closer together. Therefore, it becomes especially important to be able to manipulate intensity differentially, so that the effects of these two parameters, intensity and size, may bi examined independently of one another. Further, since for very short input exposure durations, i.e., a few hundred $\mu \mathrm{sec}$, intensity is less than for longer input durations, i.e., a few hundred $\mathrm{msec}$, it again becomes highly desirable to be able to vary input intensity independently of other display parameters. Thus, input light intensity could be made essentially equivalent for relatively short exposure durations by increasing beam voltage, or for relatively long exposures, by decreasing beam voltage. This type of control could be very important for experiments where light intensity must be held constant, while other display parameters are varied.

\section{B. Software}

In developing the software or computer programs for any computer-based CRT display system, an exceedingly large number of options are available to the programmer. He may choose, for example, to write a very short "special purpose" display program for a single experiment, or at the other extreme, he may write a very long and complicated display program that would allow one to carry out a large number of experiments. Other options, which might or might not be included, could involve the use of a TT console for S's responses, and possibly real-time analysis of these responses in order to alter future stimulus presentations to $S$ while the experiment is still in progress. Which of the alternatives is finally chosen depends in part on (1) the requirements of the research, (2) the hardware that is available, i.e., the amount of core memory capacity, the use of paper tapes vs DEC tapes, discs. or drums, the types and numbers of CRTs to be employed. etc., and (3) programming skill.

Due to our interest in visual information processing with sequential input strings, and in consideration of the hardware available (described above). it was decided to write two basic computer programs. These programs allow for considerable flexibility in generating display sequences that employ both alpha-numeric characters or straight-line segments, either separately or mixed. Earlier and more restricted versions of our current program capability may be found in Mayzner, Tresselt, \& Helfer (1967a; 1967b); some of the research results obtained with these programs are reported in Mayzner, Tresselt, \& Helfer (1967b).
The design philosophy guiding the present operational programs was to provide the experimenter (E) with as much flexibility as possible in designing a certain class of experiments. Specifically, we wished to make it possible for $\mathbf{E}$ to construct easily and quickly a very wide range of display configurations and, if desired, to store these configurations on DECtape for later use in experimental test sessions. Because of the nature of the research, no attempt was made to include in these programs options for $S$ to make his responses by using a TT console interfaced with the computer, although later programs will include such options. At present $S$ either reports his responses verbally or writes them down, depending on the particular experiment.

Specifically, with our present alpha-numeric display program, any member of the alpha-numeric character set (i.e., any one of the letters of the alphabet, any of the numerals 0-9, and any of the additional typical characters found on any typewriter keyboard. such as,,$- /,+,=, !$, etc.) may be displayed in any one of the 1600 cells of a $40 \times 40$ cell matrix. This allows for a wide variety of display configurations, such as, horizontal arrays, vertical arrays, oblique arrays, and any combinations thereof, and the number of individual inputs or characters displayed may vary from one to 100 . Since the upper limit or value of 100 inputs is a parameter value in the program, it can, with very minimal programming changes, be increased to any value desired, i.e., 500 , 1000,5000 , etc., being limited only by the storage capacity of the computer. Display times per character and also inter-character times can vary from $50 \mu \mathrm{sec}$ upwards in $50 \mu \mathrm{sec}$ increments. The 100 individual inputs can all be displayed sequentially, i.e., one character at a time, each in a different one of the 1600 cells. If desired, they may also be presented all in one cell, one input after another, or any mix of the same or different cells desired. Further, subsets of characters may be displayed simultaneously, while preserving sequentiality between subsets. Thus, one can display sequentially 100 separate characters, or 20 five-character subsets, or 1010 -character subsets. Also, any mix of subsets and subset sizes one might care to specify may be displayed in any order, display location, and display input rate desired, the only constraint being that the total number of characters displayed cannot exceed 100 characters.

The second basic display program was designed to be similar in structure to the alpha-numeric display program just described, except that instead of alpha-numeric characters, up to 100 straight-line segments may be displayed sequentially or simultaneously, in a manner equivalent to the options available with the alpha-numeric program. The only fundamental difference between the two programs is that with the alpha-numeric program, characters and cell locations are entered via the computer TT console: with the straight-line display program, the $X, Y$ coordinates of the start and end points of each line segment are entered via the computer TT console utilizing a grid of $1024 \mathrm{x}$ 1024 points. On the 340 Master Display this produces a 9-3/8 in. square raster centered on the face of the display tube.

With the two preceding display programs available, E can construct almost any type of display configuration desired, very quickly and easily, by simply typing in on the TT console the desired display parameter information, i.e., characters and their cell locations, $\mathrm{X}, \mathrm{Y}$ coordinates, character or line segment display times, inter-character or inter-line segment display times, etc. When $E$ is finished with a particular display configuration and no longer wishes it to be shown, a single switch setting on the 
accumulator switch module of the computer console allows $E$ to begin the process of constructing a new configuration. However, for purposes of experimental work, where $E$ wishes to present a number of display configurations to $S$, our present programs have an option which permits $E$ to store on a DECtape unit each separate display configuration by simple switch settings. These may later be called up for display to $S$ by means of a very fast retrieval sub-routine. This means that all the display configurations needed for any given experimental test run can be generated in advance, stored on DECtape, and then retrieved rapidly and easily during the experimental session. Further, there is really no upper limit on the number of such display configurations that can be stored, since as soon as one DECtape reel is filled, E merely places another reel on the tape drive and continues constructing and storing displays. In time a large library of experimental tapes can be constructed.

One might also wish to consider the possibility of automating the display configuration construction process entirely by writing a series of display algorithmic routines. We are currently exploring such strategies for tape preparation. However, such a strategy involves critical trade-offs between the total flexibility associats $d$ with constructing displays manually via the computer TT console and the possible restrictive nature of any particular algonthmic routine that might be developed.

With these two display programs, a number of experimental studies are possible. In the area of visual perception, any alpha-numeric array or geometric configuration (i.e., any type of $\mathrm{N}$-sided polygon composed of straight-line segments), or a mix of the two, can be constructed and displayed in an almost infinite variety of ways, i.e., sequentially, simultaneously, etc.; a variety of new spatio-temporal effects in visual information processing have already been found using these display programs (Mayzner, Tresselt, \& Helfer, 1967a; 1967b). In the areas of learning and memory, the display programs permit one to study serial learning and paired-associate paradigms, with almost total flexibility as to the type of stimulus material employed and the tíming distributions examined (Mayzner, Tresselt, Adler, Cohen, \& Schoenberg. 1966). Further, using a central computer to drive several CRTs simultaneously permits several $S$ s to be tested at the same time with absolute confidence that each $S$ is receiving identical inputs.

\section{ADVANTAGES AND DISADVANTAGES OF COMPUTER-BASED CRT DISPLAY SYSTEMS FOR CONDUCTING BEHAVIORAL RESEARCH}

It should be obvious at this point, that there are many advantages associated with a computer-based CRT display system for conducting behavioral research, at least in the areas of visual perception, learning, and memory. The extreme flexibility of input and output control via CRTs and TT consoles, the ability to control with great accuracy spatio-temporal parameters on the CRT, the capability of real-time feedback loops, the potential of testing several Ss simultaneously at individual CRT consoles, etc., are a few of the advantages cited.
The disadvantages of such systems may not appear so obvious, but some do exist. First, and foremost are the very high costs. For example, the system described in this paper cost approximately $\$ 200,000$, which is prohibitive for most experimental psychology laboratories, and the associated maintenance contract runs about $\$ 5,000$ yearly. It should be pointed out, however, that the cost of such systems is being reduced almost yearly. Also smaller systems may be obtained at substantial reductions in cost (i.e., currently in the neighborhood of approximately $\$ 20,000$ to $\$ 30,000$ ), but, of course, with concomitant decreases in flexibility of use. A second disadvantage, and of almost equal importance with initial cost, is the programming skill required to achieve full capacity of the system. We cannot emphasize too strongly that a computer-based lab of the type under discussion requires the services of a very good full-time systems programmer if powerful programs are to be developed within reasonable periods of time, i.e., from one to six months. Both of our basic display programs each fully occupy our $8 \mathrm{~K}$ of core memory, and each took approximately three man-months to write, check out, and make fully operational. ${ }^{2}$ Finally, as any system becomes larger, the probabilities of malfunction increase. So one should be prepared for computer down-time occassionally; but this disadvantage holds in varying degrees for all equipment complexes.

On balance, the advantages of a computer-based CRT display system far outnumber the disadvantages. We would, in fact, predict with considerable confidence that over the next five years some form of computer-based CRT display system will become an almost standard item of equipment in most large experimental psychology laboratories.

\section{REFERENCES}

ATKINSON, R. C., \& SHIFFRIN, R. M. Human memory: A proposed system and its control processes. Technical Report No. 110, Institute for Mathematical Studies in the Social Sciences, Stanford University, 1967.

KAHNEMAN. D. An onset-onset law for one case of apparent motion and metacontrast. Percept. \& Pstchophys. 1967, 2, 577-584.

MAYZNER. M. S. TRFSSELT, M. E., \& COHEN, A. Preliminary finding on some effects of very fast sequential input rates on perception. Psychon. Sci. 1966, 6. 513-514.

MAYZNIER. M. S., TRESSELT, M. E., \& HELFER, M. S. A research strategy for studying certain effects of very fast sequential input rates on the visual system. Psychon. Monogr. Suppl, 1967a, 2, No. 5 (Whole No. 21), $73-81$.

MAYZNER. M. S. TRLSSELT, M. F., \& HELFER, M. S. A provisional model of visual information processing with sequential inputs. Psychon. Monogr. Suppl., 1967b, 2, No. 7 (Whole No. 23), 91-108.

MAYZNER, M. S.. TRESSELT, M. E., ADLER, S., COHEN, A., \& SCHOENBERG, K. M. Short-term retention of digits: A function of itcm distribution with respect to time. Psychon. Sci, 1966, 5, 403-404.

SIDOWSKI, J. B. (Fd.) Experimental methods and instrumentation in psychology. Niw York: McGraw-Hil, 1966.

('TTAL, W. R.. \& SMITH, P. Recognition of alphabetic characters during voluntary eye movements. Percept. \& Psychophys., 1968, 3, 257-264. NOTES

1. This rescarch was supported by the Engineering Psychology Branch (Code 455) and the Personnel and Training Branch (Code 458) of the Office of Naval Research under ONR Contrast Number N00014-67-A-0467-0001 and ONR Contract Authority Number NR 196-072.

2. The author wishes to acknowledge the invaluable assistance of Mr. Nichacl S. Helfer in performing the programming work described in this paper. 